\title{
Long-Term Nikotine Administration Impairs Blood Parameters and Femoral Bone Tissue Structure in an Osteoporosis Model of Rats
}

\author{
Murat Baloğlu1, Ebru Gökalp Özkorkmaz² \\ ${ }^{1}$ Department of Physiotherapy, Diyarbakir Gazi Yasargil Education and Research Hospital, Diyarbakir, Turkey \\ ${ }^{2}$ Department of Histology and Embryology, Faculty of Medicine, Dicle University, Diyarbakir, Turkey \\ Email: ebrug76@gmail.com
}

How to cite this paper: Baloğlu, M. and Özkorkmaz, E.G. (2019) Long-Term Nikotine Administration Impairs Blood Parameters and Femoral Bone Tissue Structure in an Osteoporosis Model of Rats. Journal of Biosciences and Medicines, 7, 1-9. https://doi.org/10.4236/jbm.2019.711001

Received: October 2, 2019

Accepted: October 21, 2019

Published: October 24, 2019

Copyright () 2019 by author(s) and Scientific Research Publishing Inc. This work is licensed under the Creative Commons Attribution-NonCommercial International License (CC BY-NC 4.0). http://creativecommons.org/licenses/by-nc/4.0/

\section{Open Access}

\begin{abstract}
Osteoporosis is a systemic bone disease that results in the loss of bone mass and impared bone structure. Animal models for osteoporosis are generated by ovariectomy. Adult female Sprague-Dawley rats were divided into control, bilateral ovariectomy and bilateral ovariectomy and subcutaneous nicotine administered (received nicotine sulphate, $2 \mathrm{mg} / \mathrm{kg}$ ) groups, daily for 28 days. At the end of the period, rats were sacrified under anesthesia blood samples were taken and femoral tissues were dissected. Estrogen, calcium and alkaline phosphatase levels were measured. Tissue samples were prepared for histopathogical examination. Sections were stained with Hematoxylin and Eosin and examined under light microcope. Biochemical parameters were decreased depending on the overiectomy, also decrement was notable with nicotine intake. In the ovariectomy group; increased inflammatory cells with degenerative changes around the femoral compact bone and dilatation of osteon structures in bone trabeculae and apoptotic changes in osteocyte cells in bone lacuna were apparent. In the ovariectomy with nicotine administration group, excessive dilatation of the havers lamellae in the compact bone region, increased osteoclastic activity, picnosis and apoptotic nucleus of the osteoclastic cells located in the lacuna, and increased collagen fibers in the matrix were observed. We suggest that ovariectomy and nicotine administration together effect estrogen and calcium metabolism negatively, stimulate alterations in the structural properties of bone matrix, also affect osteocyte development and bone lamellar structure that may accelerate osteoporosis development.
\end{abstract}

\section{Keywords}

Osteoporosis, Ovariectomy, Femoral Bone, Estrogen, Histopathology 


\section{Introduction}

Affecting more than 10 million people around the World, osteoporosis is a systemic bone disease results in the loss of bone mass and impared bone structure which leads to skeletal fragility [1]. The major models for osteoporosis in human are postmenopausal osteoporosis, disuse osteoporosis and glucocorticoid-induced osteoporosis [2] [3]. Several animal models were studied until now but, rat model of osteoporosis is preferred because of their fast metabolism similar to that of human [4]. Animal models for postmenopausal osteoporosis are generated by ovariectomy. As a result of ovariectomy, estrogen deficiency is seen and bone loss occurs due to enhanced bone resorption and impaired osteoblast function [5]. Bone loss is mostly prominent in cancellous bone and the endocortical surface, caused by increased bone turnover and a negative calcium balance [6]. The production of inflammatory cytokines, including interleukin (IL)-1, IL-6, IL-7, tumor necrosis factor (TNF)- $\alpha$, and granulocyte macrophage colony-stimulating factor (GM-CSF), by immune cells is enhanced in an estrogen-deficient state [7]. These cytokines induce osteoclastogenesis and bone resorption. Osteoporotic bone shows thinning of the bone trabeculae and a general decrease in total bone tissue.

Nicotine usage has deleterious effects on health conditions such as, wound healing and vascularization [8]. Nicotine is generally administered to the body with the inhalation of tobacco smoke. Also, pharmaceutically available as chewing gum, transdermal patches, or microtablets for stopping smoking as a replacement therapy [9] [10]. The widespread nicotine intake, smoking was shown to have a negative impact on bone healing after fracture as well. Previous studies showed direct relationship between smoking and bone health by decreasing bone density and the risk of having a fracture increases [11]. Smoking increases cortisol, decreases estrogen, kills osteoblasts, impedes calcitonin, decreases oxygen supply, and decreases calcium absorption. It was shown that bone formation decreases by inhibiting periosteal cell proliferation with the acceleration of cortisol levels and also downregulate the synthesis of collagen. Also, smoking inhibits calcitonin and that leads to decreased bone formation. In post-menopausal women downregulation of estrogen causes increased bone resorption and decreased bone formation and density [12].

We assessed certain biochemical parameters in serum levels related to osteoporosis and histopathological analysis of femoral bone tissue in an ovariectomized rat model for osteoporosis with long-term nikotine administration. We suggest that this is a novel work presenting the alterations in femoral bone of ovariectomized rat model that mimics osteoporosis in human and in blood parameters related to osteoporosis.

\section{Materials and Methods}

\subsection{Experimental Animals and Nicotine Administration}

Experimental procedure was approved by the Animal Ethical Board of Dicle 
University Medical Faculty, Diyarbakır, Turkey. The standards in Guide for the Care and Use of Laboratory Animals (2011) released by National Research Council, were taken into consideration during the experiments [13]. Adult female Sprague-Dawley rats (n: 24), each weighing $180-220 \mathrm{~g}$ ( $\pm 10 \mathrm{~g})$, selected according to their estrous cycle, were obtained from Experimental Animal Laboratory Institute of Dicle University. All rats were maintained under controlled temperature at $26^{\circ} \mathrm{C} \pm 2{ }^{\circ} \mathrm{C}$ and humidity at $45 \%-65 \%$, and were kept in cages under specific pathogen-free conditions with $12 \mathrm{~h}$ light/12 h dark cycle. Food and water was available freely. After an acclimation period of a week, all rats were randomly assigned to the following groups:

1) Control group received $1.5 \mathrm{ml}$ physiologic saline solution subcutaneously for 28 days (n: 8 ).

2) Bilateral ovariectomy and $1.5 \mathrm{ml}$ physiologic saline solution subcutaneously enjected for 28 days (n: 8).

3) Bilateral ovariectomy and nicotine administration (nicotine sulphate, Sigma, Aldrich, $2 \mathrm{mg} / \mathrm{kg}$ ) subcutaneously, daily for 28 days (n: 8 ).

\subsection{Ovariectomy Procedure}

Each rat was administered intramuscular ketamine hydrochloride $(50 \mathrm{mg} / \mathrm{kg}$ ketamine hydroxide) and xylazine hydrochloride $(10 \mathrm{mg} / \mathrm{kg}$ Rompun, Bayer Istanbul, Turkey) for anesthesia. Prior to surgery, the abdominal areas of the rats were cleaned and removed from the ovarian cervical horns by making a $2 \mathrm{~cm}$ incision. The bilateral ovaries were removed from the uterine apex with silk thread. The ovariectomy was performed with 2 dorsolateral incisions modified from the metods of Park et al. [14] and Acar et al. [15]. The uterus was left in the abdominal cavity, and the abdominal area was closed with a sterile suture. After 28 days of applications, animals were sacrificed using ketamine hydrochloride (50 mg/kg ketamine hydroxide) and xylazine hydrochloride (10 mg/kg Rompun, Bayer Istanbul, Turkey) intramuscularly.

\subsection{Biochemical Analyses}

Blood samples were taken for estrogen, calcium, and alkaline phosphate (ALP) levels. Serum levels were measured using standard colorimetric methods with commercial kits (Sigma Chemical Co., Saint Louis, MA).

\subsection{Histopathological Analyses of the Femur}

To illuminate the effect of treatment to rats, the removed femoral bones were fixed with neutral buffered formalin solution, and then they were decalcified with $5 \%$ thylenediaminetetraacetic acid. Then, bone samples were directly dehydrated in a graded series of ethanol and embedded in paraffin wax. Sections of 4 - $6 \mu \mathrm{m}$ thickness, femoral bones were cut with a microtome (Rotary Microtome, Leica, RM 2265, Germany) and mounted on coated slides. Sections were stained with hematoxylin and eosin for observation by light microscopy (Zeiss, Germany). 


\subsection{Statistical Analysis}

Statistics and analyzes were performed using the SPSS 22.0 for Windows. In the analysis of the data, Mann-Whitney $U$ non-parametric statistical tests was used in the intergroup comparisons depending on the variables and the results were given as the mean \pm standard deviation. The results were considered statistically significant for $\mathrm{p}<0.05$.

\section{Results}

\subsection{Biochemical Results}

Biochemical data were compared between the groups. A significant difference was found between control, ovariectomy and ovariectomy + nicotine administered group (Table 1). Estrogen levels were decreased significantly in the ovariectomy group, were also decreased in the ovariectomy + nicotine administered groups when compared to control group. Calcium levels were lower in the ovariectomy group, also significantly decreased in ovariectomy + nicotine administered group. ALP levels were statistically higher in the ovariectomy group, however, close to the control in ovariectomy + nicotine administered group.

\subsection{Histopathological Results}

In the histopathological examination of the control group sections; in the compact bone region, chromatin-rich nuclei of the osteblast cells embedded in the lacuna, havers channels in lamellar structures are arranged parallel to each other, with regular wolkmann channels. Bone matrix density is normal and dense basophilic around osteon structures (Figure 1). The femoral bone sections of the ovariectomized group were increased in some inflammatory cells with degenerative changes around the compact bone.Dilatation of osteon structures in bone trabeculae and apoptotic changes in osteocyte cells in bone lacuna were observed

Table 1. Biochemical parameters of all studied groups.

\begin{tabular}{|c|c|c|c|c|}
\hline Parameter & Groups & $n$ & $M e a n \pm S D$ & $\begin{array}{c}\text { Mann-Whitney } \\
\text { U Test value } \\
(\mathrm{p}<0.05)\end{array}$ \\
\hline \multirow{3}{*}{$\begin{array}{c}\text { Estrogen } \\
\mathrm{mg} / \mathrm{ml}\end{array}$} & 1) Control & 8 & $6.12 \pm 0.28$ & $\star 2, * 3$ \\
\hline & 2) Ovariectomy & 8 & $1.42 \pm 0.28$ & $\star 1, * 3$ \\
\hline & 3) Ovariectomy + nicotine adm & 8 & $3.79 \pm 0.12$ & $\star 2$ \\
\hline \multirow{3}{*}{$\begin{array}{c}\text { Calcium } \\
\mathrm{mg} / \mathrm{dl}\end{array}$} & 1) Control & 8 & $9.32 \pm 0.24$ & $\star^{\star} 2$ \\
\hline & 2) Ovarectomy & 8 & $6.88 \pm 0.24$ & ${ }^{* *} 1, * * 3$ \\
\hline & 3) Ovariectomy + nicotine adm & 8 & $4.78 \pm 0.28$ & $\star 2$ \\
\hline Alkaline & 1) Control & 8 & $27.12 \pm 0.78$ & $\star 2$ \\
\hline \multirow{2}{*}{$\begin{array}{c}\text { phosphatase } \\
\mathrm{mg} / \mathrm{dl}\end{array}$} & 2) Ovariectomy & 8 & $32.0 \pm 0.92$ & ${ }^{*} 1, * 3$ \\
\hline & 3) Ovariectomy+nicotine adm. & 8 & $26.12 \pm 0.78$ & $\star 2$ \\
\hline
\end{tabular}

${ }^{*} \mathrm{p}<0.05$; Statistically significant. 
(Figure 2). In the histopathological examination of the ovariectomized + smoking group, excessive dilatation of the havers lamellae in the compact bone region, increased osteoclastic activity, picnosis and apoptotic nucleus of the osteoclastic cells located in the lacuna, and increased collagen fibers in the matrix were observed (Figure 3).

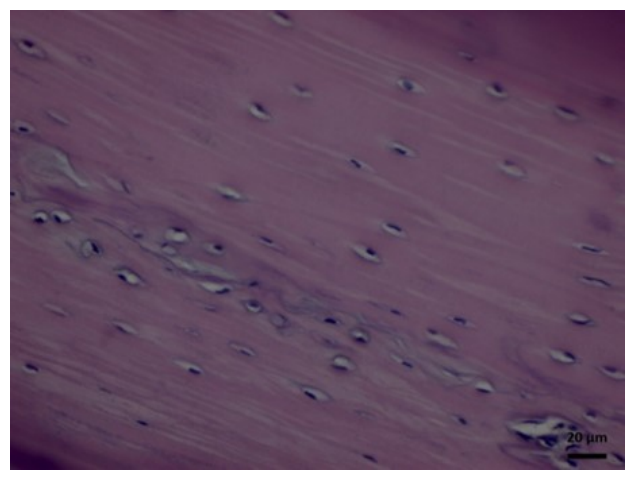

Figure 1. Control group; compact bone region, chromatin-rich nuclei of the osteblast cells in the lacuna, havers channels in lamellar structures arranged parallel to each other, regular wolkmann channels. Normal bone matrix density and dense around osteon structures, H-E staining Bar: $20 \mu \mathrm{m}$.

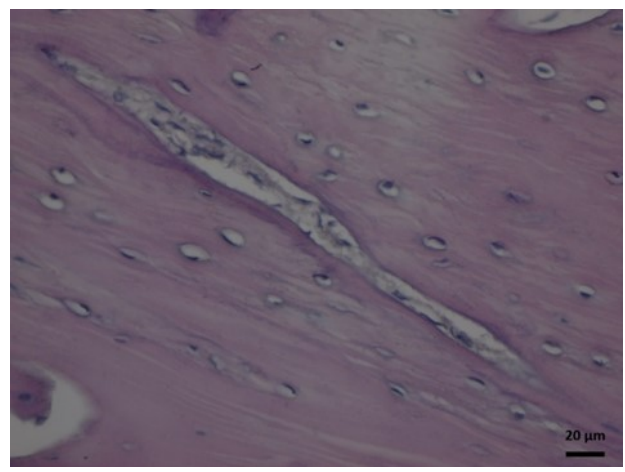

Figure 2. Ovariectomy group; increased inflammatory cells with degenerative changes around the femoral compact bone. Dilatation of osteon structures in bone trabeculae and apoptotic changes in osteocyte cells in bone lacuna, H-E staining Bar: $20 \mu \mathrm{m}$.

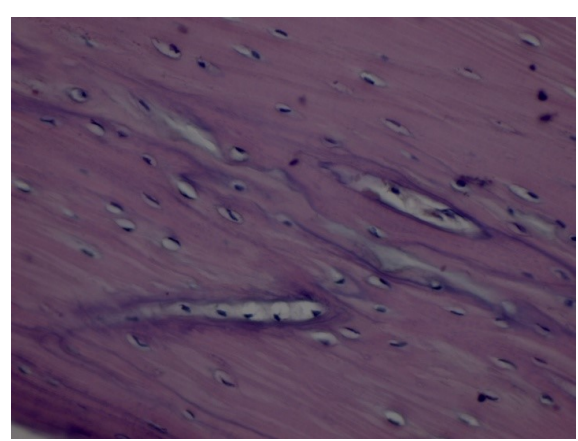

Figure 3. Ovariectomy and nicotine group; excessive dilatation of the havers lamellae in the compact bone region, increased osteoclastic activity, picnosis and apoptotic nucleus of the osteoclastic cells located in the lacuna, and increased collagen fibers in the matrix, H-E staining Bar: $20 \mu \mathrm{m}$. 


\section{Discussion}

Osteoporosis, is a major age-related disease, caused by the imbalance in bone formation-osteoblast activity and bone resorption-osteoclast activity, influenced by diet, physical activities, hormonal status, cytokines, and clinical status etc. [16] [17].

One of the main types of osteoporosis in human is postmenopausal osteoporosis and it can be created in animal models by ovariectomy. In rats, the effects of ovariectomy were examined and significant bone loss after ovariectomy was observed in the proximal tibial metaphysis after 14 days, in the lumbar vertebral body after 60 days, and in the femoral neck after 30 days [18] [19] [20]. In fact, the rate of loss of bone mass in male and female rats is highly dependent on the method used to induce osteoporosis and the site evaluated and whether this loss concerns cancellous or cortical bone [21]. The skeletally mature rat is an appropriate animal model for the research of postmenopausal osteoporosis. However, all experimental osteoporosis protocols can be implemented in skeletally immature or mature rats [22]. Although rats reach sexual maturity at the age of 2.5 months, their skeleton is considered mature after the age of 10 months [23]. If skeletally immature rats are involved, then a low peak bone mass is achieved, a fact that is considered to be a high risk factor for human osteoporotic fractures. Researchers suggested that skeletally immature rat is an appropriate animal model in the research of endocrine, nutritional and environmental factors, all of which can influence peak bone mass [24]. We used immature rats in our study to evaluate the effects of smoking.

After ovariectomy, in cortical bone, bone resorption is enhanced in the endosteum and bone formation is enhanced in the periosteum leading to an enlarged bone marrow cavity. The reduction of cortical thickness and enlargement of the bone marrow cavity begin between 90 and 120 days after ovariectomy [25]. Bone remodeling occurs through osteoblast activity for bone formation via the synthesis of bone matrix, and through osteoclast activity for the degradation of bone matrix. The equilibrium between the activities of these two cells maintains the mineral homeostasis. Osteoporotic bone shows an increase in the length of the remodeling cycle and reduced capacity to lay down a new mineralized bone matrix. In our study, the ovariectomy group depicted increased inflammatory cells with degenerative changes around the femoral compact bone. Dilatation of osteon structures in bone trabeculae and apoptotic changes in osteocyte cells in bone lacuna. In the ovariectomy and nicotine administered group excessive dilatation of the havers lamellae in the compact bone region, increased osteoclastic activity, picnosis and apoptotic nucleus of the osteoclastic cells located in the lacuna, and increased collagen fibers in the matrix were observed.

In animal models researches indicated that nicotine inhibits the expression of genes related to osteogenic activity [BMPs, TGF- $\beta$, alkaline phosphatase (ALP), platelet-derived growth factor (PDGF), vascular endothelial growth factor (VEGF), receptor activator of nuclear factor kappa-B ligand (RANKL), and os- 
teoprotegerin (OPG)], especially in high doses [26] [27]. In our study, estrogen and calcium levels were decreased significantly in the ovariectomy group, were also decreased in the ovariectomy + nicotine administered groups when compared to control group. ALP levels were statistically higher in the ovariectomy group, however, close to the control in ovariectomy + nicotine administered group.

\section{Conclusion}

Taking into account all these considerations in the present study, we evaluated that ovariectomy and nicotine administration together effect estrogen and calcium metabolism negatively, stimulate alterations in the structural properties of bone matrix, osteocyte development and bone lamellar structure may influence osteoporosis development. In this sense, future studies with different techniques are needed to uncover the alterations in tissues resulting from the dual role of osteoporosis and nicotine intake.

\section{Conflicts of Interest}

The authors declare no conflicts of interest regarding the publication of this paper.

\section{References}

[1] Ishimi, Y. (2015) Osteoporosis and Lifestyle. Journal of Nutritional Science and Vitaminology, 61, S139-S141. https://doi.org/10.3177/jnsv.61.S139

[2] Ochi, H. and Takeda, S. (2011) Animal Models for Bone and Joint Disease. The Genetically-Modified Mice as a Tool for Osteoporosis Research. Clinical Calcium, 21, 226-232.

[3] Oheim, R., Schinke, T., Amling, M. and Pogoda, P. (2016) Can We Induce Osteoporosis in Animals Comparable to the Human Situation? Injury, 47, S3-S9. https://doi.org/10.1016/S0020-1383(16)30002-X

[4] Quinn, R. (2005) Comparing Rat's to Human's Age: How Old Is My Rat in People Years? Nutrition, 21, 775-777. https://doi.org/10.1016/j.nut.2005.04.002

[5] Komori, T. (2015) Animal Models for Osteoporosis. European Journal of Pharmacology, 759, 287-294. https://doi.org/10.1016/j.ejphar.2015.03.028

[6] Christiansen, C. and Lindsay, R. (1990) Estrogens, Bone Loss and Preservation. Osteoporosis International, 1, 7-13. https://doi.org/10.1007/BF01880410

[7] Pacifici, R. (2008) Estrogen Deficiency, T Cells and Bone Loss. Cellular Immunology, 252, 68-80. https://doi.org/10.1016/j.cellimm.2007.06.008

[8] Saldanha, J.B., Pimentel, S.P., Casati, M.Z., Sallum, A.W., Sallum, E.A. and Nociti, F.H. (2004) Histologic Evaluation of the Effect of Nicotine Administration on Bone Regeneration. A Study in Dogs. Brazilian Oral Research, 18, 345-349. https://doi.org/10.1590/S1806-83242004000400013

[9] Baron, J.A. (1996) Beneficial Effects of Nicotine and Cigarette Smoking: The Real, the Possible and the Spurious. British Medical Bulletin, 52, 58-73.

https://doi.org/10.1093/oxfordjournals.bmb.a011533

[10] Yorgancilar, E., Tunik, S., Deveci, E., Gun, R., Bakir, S., Kinis, V., et al. (2012) The 
Effects of Systemic Use of Nicotine on the Rat Nasal Mucosa: A Histopathologic and Immunohistochemical Study. International Journal of Morphology, 30, 829-833. https://doi.org/10.4067/S0717-95022012000300010

[11] Bhandari, M., Fong, K., Sprague, S., Williams, D. and Petrisor, B. (2012) Variability in the Definition and Perceived Causes of Delayed Unions and Nonunions. The Journal of Bone and Joint Surgery, 94, 1091-1096. https://doi.org/10.2106/JBJS.K.01344

[12] Berman, D., Oren, J.H., Bendo, J. and Spivak, J. (2017) The Effect of Smoking on Spinal Fusion. International Journal of Spine Surgery, 11, 229-238. https://doi.org/10.14444/4029

[13] National Research Council (2011) National Research Council Guide for the Care and Use of Laboratory Animals. 8th Edition, The National Academies Press, Washington DC.

[14] Park, S.B., Lee, Y.J. and Chung, C.K. (2010) Bone Mineral Density Changes after Ovariectomy in Rats as an Osteopenic Model: Stepwise Description of Double Dorso-Lateral Approach. Korean Neurosurgery Society, 48, 309-312.

https://doi.org/10.3340/jkns.2010.48.4.309

[15] Acar, Z., Deger, U., Görkem, Ü., Togrul, C., Deveci, E., Kaya, S. and Ekinci, S. (2016) Effects of Potentilla fulgens on Tuba Uterina in Ovariectomized Rats. International Journal of Morphology, 34, 460-464. https://doi.org/10.4067/S0717-95022016000200008

[16] Rizzoli, R., Bruyere, O., Cannata-Andia, J.B., et al. (2009) Management of Osteoporosis in the Elderly. Current Medical Research and Opinion, 25, 2373-2387. https://doi.org/10.1185/03007990903169262

[17] Watts, N.B., Lewiecki, E.M., Miller, P.D. and Baim, S. (2008) National Osteoporosis Foundation 2008 Clinician's Guide to Prevention and Treatment of Osteoporosis and the World Health Organization Fracture Risk Assessment Tool (FRAX): What They Mean to the Bone Densitometrist and Bone Technologist. Journal of Clinical Densitometry, 11, 473-477.

[18] Li, M., Shen, Y. and Wronski, T.J. (1997) Time Course of Femoral Neck Osteopenia in Ovariectomized Rats. Bone, 20, 55-61. https://doi.org/10.1016/S8756-3282(96)00317-1

[19] Wronski, T.J., Cintron, M. and Dann L.M. (1988) Temporal Relationship between Bone Loss and Increased Bone Turnover in Ovariectomized Rats. Calcified Tissue International, 43, 179-183. https://doi.org/10.1007/BF02571317

[20] Wronski, T.J., Dann, L.M. and Horner, S.L. (1989) Time Course of Vertebral Osteopenia in Ovariectomized Rats. Bone, 10, 295-301. https://doi.org/10.1016/8756-3282(89)90067-7

[21] Lelovas, P., Xanthos, T., Thoma, S., Lyritis, G. and Dontas, I. (2008) The Laboratory Rat as an Animal Model for Osteoporosis Research. Comparative Medicine, 58, 424-430.

[22] Shen, V., Birchman, R., Liang, X.G., Wu, D.D., Lindsay, R. and Dempster D.W. (1997) Prednisolone Alone, or in Combination with Estrogen or Dietary Calcium Deficiency or Immobilization, Inhibits Bone Formation but Does Not Induce Bone Loss in Mature Rats. Bone, 21, 345-335. https://doi.org/10.1016/S8756-3282(97)00153-1

[23] Jee, W.S.S. and Yao, W. (2001) Overview: Animal Models of Osteopenia and Osteoporosis. Journal of Musculoskeletal and Neuronal Interactions, 1,193-207.

[24] Turner, R.T., Lotinun, S., Hefferan, T., Evans, G.L., Zhang, M. and Sibonga, J.D. 
(2001) Animal Models for Osteoporosis. Reviews in Endocrine and Metabolic Disorders, 2, 117-127. https://doi.org/10.1023/A:1010067326811

[25] Danielsen, C., Mosekilde, L. and Svenstrup, B. (1993) Cortical Bone Mass, Composition, and Mechanical Properties in Female Rats in Relation to Age, Long-Term Ovariectomy, and Estrogen Substitution. Calcified Tissue International, 52, 26-33. https://doi.org/10.1007/BF00675623

[26] Wong, L.S., Green, H.M., Feugate, J.E., Yadav, M., Nothnagel, E.A. and Martins-Green, M. (2004) Effects of "Second-Hand" Smoke on Structure and Function of Fibroblasts, Cells that Are Critical for Tissue Repair and Remodeling. BMC Cell Biology, 5, 13. https://doi.org/10.1186/1471-2121-5-13

[27] Ma, L., Zwahlen, R.A., Zheng, L.W. and Sham, M.H. (2011) Influence of Nicotine on the Biological Activity of Rabbit Osteoblasts. Clinical Oral Implants Research, 22, 338-342. https://doi.org/10.1111/j.1600-0501.2010.02088.x 